\title{
Operation Models of Interactive Learning
}

\author{
Mu-Yan HUANG ${ }^{1, a}$, Yong-Zhi LIU ${ }^{1, b, *}$ \\ ${ }^{1}$ No.1, Dongsanlu, Erxianqiao, Chenghua District, College of Foreign Languages and Cultures, \\ Chengdu University of Technology, 610059, Chengdu, P.R.China \\ a307493324@qq.com, b lyzhi@cdut.edu.cn \\ ${ }^{*}$ Corresponding author
}

Keywords: Higher Education; Teaching Model; Cooperation; Information Exchange

\begin{abstract}
Interactive learning is a practical teaching theory, which is valuable to improve students' comprehensive qualities. However, it is not widely adopted in Chinese higher education system for the lack of specific operative teaching methods. Through the analysis of concrete classroom teaching methods and outdoor teaching activities, such as interactive learning model of playing games, multimedia, case analysis, peer instruction and network teaching, it is made much easier for teachers to reference various teaching approaches, hence making it possible to popularize interactive learning.
\end{abstract}

\section{Introduction}

New trend of thoughts has brought new direction for teaching reform with the development of science and technology. To improve students' innovative ability, critical thinking, cooperative ability, material collection and analysis ability, higher education system is now trying various explorations [1]. In recent years, Interactive learning model based on constructivism theory has drawn attention all over the world. Palincsar, a professor in University of Michigan, put forward the concept of interactive teaching in classroom in 1970s, which is now called interactive learning or interactive teaching. Interactive learning is a new type of cooperative teaching theory, emphasizing on assisting students and teachers to communicate or exchange information in a cooperative way through various methods. These years, most of the researches are mainly about single model on single discipline, such as English, Politics or Physics under a certain teaching model. Therefore, as for specific operative teaching methods suitable for higher education, more aspects need to be explored.

\section{The Tactics of Interactive Learning}

Constructivism theory proposes that learning is an interactive process, teaching is usually combined with a series of techniques to form the unique learning style, by which it could create knowledge. And the genetic epistemology is a basis for instructional design. What's more, the theory of behaviorism, cognitive theory, social learning theory and relevance theory are also available. In that case, it follows certain principles. One is the cooperative principle, which refers to the maxims of communication (H. P. Grice). They are maxims of quality, quantity, relevance and manner [2]. The other one is the principle of developing students' initiative, it proposes the central role of students in teaching activities. With the guidance of democratic principles, it will be easier for teachers to create a peaceful, free and independent learning environment. Furthermore, teachers should consider six tactics: firstly, make sure that all the students participate actively. Second, constructivism holds that knowledge is actively constructed by the cognitive subject, so the teachers should let students find problems by themselves and then participate in the construction process of cognitive structure. Third, let students stay in a relatively free state to develop their initiative and creativity. Teachers could design questions in advance, to rouse students' experience, intention and creativity, and then let them discuss. Fourth, keep good atmosphere in class. Fifth, keep democracy and equality in class. Maintain good relationship with students. Sixth, pay more 
attention to the process assessment. Compared with the traditional teaching model, Interactive teaching model is more scientific and reasonable. The results are as follows.

[Differences between traditional teaching mode and interactive learning model] [3]

\begin{tabular}{|l|l|l|}
\hline Number & $\begin{array}{l}\text { Main characteristics of } \\
\text { traditional teaching model }\end{array}$ & Main characteristics of interactive learning model \\
\hline 1 & Teacher-oriented instruction & Students- oriented learning \\
\hline 2 & Single sense way of stimulation & Multisensory ways of stimulation \\
\hline 3 & Single method & Multiple methods \\
\hline 4 & Single media & multimedia \\
\hline 5 & Isolated work & Cooperative study \\
\hline 6 & Information transmit & Information exchange \\
\hline 7 & Text reading ability & Text understanding ability and Practical experience \\
\hline
\end{tabular}

\section{Specific Teaching Models of Interactive Learning:}

\section{Classroom Interaction Model [4]}

Classroom interaction model could be achieved by changing teaching methods with different methods in classes. Teachers need to keep the following basic requirements: firstly, know your students, containing the learning background and interests; secondly, arrange teaching blueprint properly, pay attention to the subject of modeling and try to develop students' metacognitive ability. Modeling discipline mainly refers to the methods by using the related language and approaches to abstract and simplify the practical problems. Metacognition is about personal cognitive process and the ability to regulate it, including the comprehension and controlling of thinking and learning activities. In essence, it is self-conscious and self-regulation. Finally, establish good relationship with students and complete the task of teaching cooperatively on the basis of equal opportunities for dialogue.

\section{Game-based Interactive Teaching Model [5]}

Under this kind of model, teachers could communicate with students to filter or design a suitable game, combining with the teaching content. This type of model has four steps: designing, props preparing, task completing and summarizing. According to specific characteristics of teaching contents and subjects, teachers should first choose the most suitable game (information could be selected from networks, television programs, books, newspapers and other channels, or brainstorming with students). Meanwhile, there should be a plan for emergency. Secondly, prepare the tools and arrange game scene in advance. Finally, be flexible in accordance with established programs and then summarize the entire task. There are three requests for teacher: first, setting the game based on teaching contents. Second, when setting the roles, it is necessary to consider students' self-initiative. The roles of students had better be the players, which could ask the teacher or classmates for help. While, the teachers better not to be the players, instead, the characters of administrator or substitute roles could be the best choice. Non-player role or administrator role could help keep order, and the substitute one can strengthen the interaction between teachers and students. Third, better to consider multiple choices of participants, let students play different roles to accomplish the task cooperatively. College English curriculum, for example, can be designed as finding the pair words game to review the text words. Teachers put the pictures of related target words on the blackboard, with the corresponding word cards upside down on the lectern, and students need to pick out the right one.

\section{Multimedia Presentations Interactive Teaching Model}

Multimedia presentations interactive teaching model means to exchange information through tools, such as projector, computers, projectors, interactive board. With text, sound, images, animation, video files and other forms, it can improve students' learning interest through visual or 
auditory stimulation. There are three main steps: data preparation, multimedia presentation and feedback summary. First, download related videos, pictures, music, network resources etc, or require students to prepare for it in advance. It can be regarded as one of the assessment contents. Then, interact with students, let them demonstrate it after preparation. At last, summarize. Process evaluation can be adopted in this kind of model. Teachers should list specific charts to the appraisal of students' performance. What's more, here comes a new tool in Interactive learning, the electronic blackboard. It has two separate functions: display and interaction. As a display tool, it provides teachers with the function of using the file, the specific contents of software, or network resources. As an interactive tool, it allows users to write or manipulate objects including images and texts. Teachers can use this tool to create a real context under all kinds of virtual background, such as the virtualization of classroom into the conference room, laboratory, or a certain state city, etc. During the teaching process, teachers should pay attention to the proper choice of network resources and appropriate use of multimedia to create a pleasant learning atmosphere. For example, as for the oral English teaching curriculum, teachers may first use the electronic blackboard to play movies or video clips, give students the difficult points of it during broadcast process, then let the students have conversations under such context. In college science and engineering courses, for example, the mathematics physics or chemistry curriculum, teacher can change the classroom into a lab with the aid of multimedia images, and establish a scientific research team, let students participate in brain storming actively.

\section{Case Discussion-based Interactive Model}

Case discussion-based interaction model regards students as the main bodies, it is a kind of method to form a cooperative interaction between students and teachers through the analysis and discuss of various related cases. Usually there are six steps: case selection, theory study, case elaboration, suspense, plan analysis, and feedback summary. First, teachers should select proper cases through different channels, such as newspapers, magazines or network resources, etc. The choices could be the current hot spots or typical cases. Then, choose proper time according to in advance. At last, analyze the cases. It could be done in a way of class discussion, such as group discussion or table discussion. This kind of model needs to focus on the examples in real life to stimulate students' curiosity, let them learn to combine theory with practice, to think and explore issues actively. For example, when teaching an introduction to earth science curriculum, teachers could use the case of Long Menshan fault zone in the Wenchuan earthquake in 2008 to analyze the relationship between Fault zone and the earthquake.

\section{Peer Instruction Interactive Model}

Eric Mazur (physics professor of Harvard University) proposed the concept peer instruction [6]. It is an interactive learning method based on the theory of cooperative study, which is mainly for large class teaching. Companions could increase awareness of autonomous learning by questioning and explaining with each other. In that case, they could solve the problems through further exploration and reorganize their personal knowledge or conclusions of the topic. Usually there are five steps: questions presentation, students answer (individual), group study and discussion, results showing (in group), and feedback summary. First, ask students to think independently and write personal opinions. Then, divide students into several groups and elect a team leader for each group, the performance of group members could influence the scores of whole group. Each group should study cooperatively and construct relevant knowledge collectively. In the discussion stage, each group member needs to state the viewpoint while the team leader should record it. At last, each group presents its collective ideas and the teachers comment or summarize the task when necessary. As for the model of evaluation, better to pay more attention to process evaluation, it can be done in one group, different groups or by teachers. For the team whose performance is rather excellent in cooperative problem solving, better to give them consistent affirmative or individual rewards and record it in the final examination. When taking this kind of model, teachers should consider the following rules: first, the students' level of knowledge should be different in a same group. Second, teachers participate in discussions and give authoritative interpretation of teaching content when 
necessary. Third, keep classes in order. For example, to explain a physics phenomenon, teachers can ask students to collect information in advance, let them list personal points of view. Then they can discuss with team members, integrate information, analyze experiment and complete the task cooperatively.

\section{Extracurricular Activities Model}

\section{Network Interactive Learning Model}

Network interactive learning model refers to the way to use the modern technology (such as QQ, MSN, blogs etc) to realize the communication and study between students and teachers. Usually there are five steps: platform settling, friends adding, grouping, communicating, feedback summary and questions solving. Teachers should choose proper platform which is available for all the classmates. Then a group can be settled down, which can be further divided into different smaller groups according to the specific situations. After that, ask students to search for the materials on the internet and screen out the useful information to share with their classmates. The assessment model could be various, accordance with the performance of each student. Here on internet teaching model, teachers need to obey three basic rules. First, strengthen the supervision, avoid digressing of the teaching objectives. Second, attach great importance to the emotional communication with students. Third, update and share information in time. One of the specific ways of network based interactive learning is to create microblog class [7]. It refers to the interactive teaching activities based on microblog service platform. Teachers and students can use microblog platform to share information, chat privately and discussion. By sharing all sorts of relevant information they can carry out the discussion activities easily. After choosing one or two of classmates to supervise and control the background platform, this kind of interactive learning can be carried out in order. Microblog class could also follow the subjects-related registered users to expand knowledge, enrich the learning contents, such as @ Pocket English, @ Classic English. Through further interaction between teachers and students, network interactive learning method can help create a relaxed and harmonious learning atmosphere, which could arouse students' positive emotional factors and establish their learning confidence and interest. Meanwhile, it can also help increase the intangible extracurricular learning time because students may spend a lot of time searching for the internet.

\section{Extracurricular Face-to-Face Interactive Model}

Extracurricular interactive model tends to complete the interactive communication by extracurricular activities or social practice activities. There are six steps: activity setting, program designing, data preparation, site layout, activities implement, and feedback summary. The types of activities could be various. For example, keynote speech contest can help deepen the understanding of specific concepts or phenomena, the debate competition could exercise students' thinking and logical reasoning ability, cooperative sports game could deepen the relationship between students and teachers. When designing the project, it is necessary to consider the purpose, the time, the place, the process, the tools and also the contingency plan. What's more, to exercise their practice abilities, it is better to guide students in participating in data preparation process and also the layout phase. As for the assessment methods, better to combine both process evaluation and results evaluation. Meanwhile, in extracurricular activities, teachers need to consider four aspects. First, prepare contingency plans carefully to ensure safety. Second, choose meaningful activities. Third, ensure proper interactions between teachers and students. Fourth, let students in a state of relative freedom, so as to inspire their initiative creativities. One feasible way is the Social Practice Activity, which is a bridge for students to connect with the society.

\section{Conclusion}

It cannot be called real education without communication between teachers and students. Teaching activity is not a mechanical intelligent operating system, but a manual controlling model which needs information interaction and internal communication of participants. There is a saying 
that it's better to teach a man fishing than to give him a fish. So as for education, it is also better to make the students master the learning rules rather than just give them the knowledge itself. Nowadays, students are having difficulty in meeting with the needs of society under the traditional teaching model, thus the reformation is extremely urgent. Teaching reform should adapt to the transformation of traditional education thought to the modern education thought, to cultivate students' innovative thinking, enhance their application abilities to obtain knowledge and create knowledge. Students are not passive recipients of knowledge. Instead, they are positive information processors. Ideas of interactive learning could help students grasp learning contents more profoundly and help teachers expand their scope of basic teaching process through the information exchange interaction. From the beginning of the 20th century, foreign college students began to be fond of learning on the internet. They hope to get information through various channels. Nowadays, interactive learning models are largely applied in the schools of America and also most of the western countries. However, it has not been widely used in most of the developing countries yet. The fundamental way of changing the situation is to update the teaching concepts and try new teaching models constantly. Currently, researches in interactive learning are being in a relatively immature stage in China, more aspects need to be explored.

\section{Acknowledgement}

This research was financially supported by the National Social Science Fund Project (SC12WY020) and Research Fund for Excellence in Chengdu University of Technology, 2013.

\section{References}

[1]. Qi-quan ZHONG, The Development of Modern Teaching Theory, Education science press Beijing, 1999.

[2]. Zhuang-ling HU, Linguistics a Course Book [M]. Peking University Press, Beijing, 2006.9-191.

[3]. Sessoms, D. Interactive instruction: Creating interactive learning environments through tomorrow's teachers. International Journal of Technology in Teaching and Learning, 2008 4(2)86-89.Information on http://www.sicet.org/journals/ijtt1/issue0802/4_2_1_Sessoms.pdf

[4].Cai-juan CHEN, the establishment and implementation of Multi-dimensional interactive teaching model- - In the perspective of ideological and political theory course. Heilongjiang Higher Education Research, Heilongjiang, 2008(11)147-150

[5]Ni ZHANG, Yi ZHANG, Kui-yuan ZHAN, An analysis of Game-based Interactive Teaching Model in Chinese as a foreign language, Modern education technology, 2009(5)58-61.

[6]Ping ZHANG, Qingyun TU, Yan-ping MO, Cooperative learning in class- Peer Instruction helps promote the learning of Physical concepts, China's university teaching, 2012(6)56-59.

[7].Yun ZHOU, A Research of Microblog Class and Interactive Learning Model, Modern education technology, 2012(2)79-84. 